\title{
Evaluation of Work-Related Symptoms by Job Exposure Matrix in Chronic Pulmonary Diseases - A Cross- sectional Study
}

\author{
Lahya Afshari Saleh, MD; Atefeh Matoori, MD²; Reza Basiri, MD³ Habibollah Esmaily, PhD; Farzaneh Rahimpour, MD²; \\ Roshanak Hazrati, MD²; Mahnaz Amini, MD ${ }^{3 *}$ \\ 1Department of Occupational Medicine, Division of Sleep Medicine, Psychiatry and Behavioral Sciences Research Center, Mashhad \\ University of Medical Sciences, Mashhad, Iran \\ ${ }^{2}$ Department of Occupational Medicine, School of Medicine, Mashhad University of Medical Sciences, Mashhad, Iran \\ ${ }^{3}$ Lung Disease Research Center, Mashhad University of Medical Sciences, Mashhad, Iran \\ ${ }^{4}$ Department of Epidemiology \& Biostatistics, Faculty of Hygiene, Mashhad University of Medical Sciences, Mashhad, Iran
}

\begin{abstract}
Background: Despite the high prevalence of occupational airway disorders, they are usually underestimated by physicians. This study designed to study the prevalence of work-related symptoms (WRS) and their association with occupational exposure in outpatient pulmonary clinics.

Methods: Adults with more than one year of lower respiratory symptoms were included. Retired patients, housewives and those unable to perform spirometry were excluded. Demographic, anthropometric and medical data were documented. The Persian version of National institute for health and safety respiratory questionnaire was used to classify job titles. WRS were defined as 2 (or more) positive questions with improvement of symptoms on days off work. Job exposure matrix (JEM) was used for classifying the type of occupational exposure into one of three categories: high molecular weight (HKW), low molecular weight (LMW) and mixed.

Results: A total of 250 patients $(69 \%$ male) with mean $( \pm$ SD) age of $40( \pm 11.6)$ years, 178 cases of asthma and 59 chronic obstructive pulmonary disease (COPD) cases entered. Occupational exposure was seen in $51.2 \%$ of patients $(26,51$ and 51 cases with HMW, LMW and mixed, respectively). WRS were lower in those who exercised regularly (24.6\% vs. $39.4 \%)$ and higher in those with eczema (62.5\% vs. $33.6 \%$ ). Eczema had an odds ratio (OR) of 4.13 (95\% Cl 1.3 to $12.9, P=0.01$ ). Exposure to LMW almost tripled the risk of WRS (OR: $2.9,95 \% \mathrm{Cl}: 1.4$ to $5.9, P=0.003$ ) in our patients.

Conclusion: Pulmonologists are firmly advised to take their patients' occupational and vocational exposures into consideration for treatment plans, especially in those with positive history of eczema and exposure to LMW.

Keywords: Bronchial asthma, COPD, Job exposure matrix, Respiratory questionnaire

Cite this article as: Afshari Saleh L, Matoori A, Basiri R, Esmaily H, Rahimpour F, Hazrati R, et al. Evaluation of work-related symptoms by job exposure matrix in chronic pulmonary diseases - a cross-sectional study. Arch Iran Med. 2021;24(9):696-700. doi: 10.34172/aim.2021.100
\end{abstract}

Received: October 1, 2019, Accepted: October 28, 2020, ePublished: September 1, 2021

\section{Introduction}

Respiratory system is one of the main targets of occupational hazards. ${ }^{1}$ Inhalation of different types of particles produced in many jobs causes a wide array of respiratory disorders, including upper airway irritation, bronchial asthma, chronic obstructive pulmonary disease (COPD), interstitial lung disease, lung cancer, pulmonary infections and pleural effusion.

Asthma and COPD are two major chronic airway disorders affecting more than 400 million people all over the world with link to the workplace factors in up to $15 \%$ of asthmatics and $15 \%-20 \%$ of COPD cases. $^{2,3}$ Pulmonologists are frequently advised to ask about their patients' current and previous jobs. Apart from well-known health effects of famous pneumoconioses such as silicosis and asbestosis, hazards of other less studied occupational lung diseases are usually underestimated by employers, employees and physicians. This study was designed to evaluate the prevalence of work-related symptoms (WRS) and the possible role of less-known occupational exposures in patients with chronic respiratory symptoms visited in outpatient pulmonary clinics.

\section{Materials and Methods}

This is a cross-sectional study on patients who presented to an outpatient pulmonary clinic (blinded upon journal's request) of Mashhad University of Medical Sciences (MUMS), Mashhad, Iran.

Participant or their guardians were informed about the aims and design of the study. All subjects 18-60 years of age with complaints of at least 12 months of respiratory symptoms entered the study. Those in acute exacerbations 
of chronic pulmonary disease, unable to perform spirometry, or retired from their work in the last year were excluded from the study. In order to reduce the bias of household exposures, we also excluded women working mainly as housewives. Pulmonologists interviewed the participants and reviewed their medical records in order to ascertain a final diagnosis for their chronic pulmonary symptoms. The participants were then visited by an occupational medicine specialist for completion of demographic, anthropometric and medical data (age, sex, body mass index [BMI], college education, more than 3 hours per week exercise, and marital status, history of smoking, eczema, respiratory medication, job category, job duration, and current use of personal protective equipment).

The volume of air expelled in the $1^{\text {st }}$ second of forced expiration $\left(\mathrm{FEV}_{1}\right)$ during simple spirometry was used for classification of pulmonary disease severity according to the ATS/ERS criteria as follows: $\mathrm{FEV}_{1}>70 \%$ : mild; $\mathrm{FEV}_{1}=$ 60-69\%: moderate; $\mathrm{FEV}_{1}=50-59 \%$ : moderate to severe; $\mathrm{FEV}_{1}=35$-49: severe; and $\mathrm{FEV}_{1}<35 \%$ : very severe. ${ }^{4}$

Respiratory symptoms were assessed by the National Institute for Occupational Safety and Health (NIOSH) respiratory questionnaire and job exposure matrix (JEM).

a) The validated Persian version of the NIOSH respiratory questionnaire, ${ }^{5}$ with 32 items consists of three parts: demographic characteristics, occupational data and respiratory assessment over the past year. Presence of at least 2 respiratory symptoms which improves on days away from work is defined as WRS. The NIOSH respiratory questionnaire was completed by all participants and the result reported as the proportion of "WRS".

b) JEM is a database used in epidemiologic studies in order to specify the type of exposure in a job title. $^{6}$ It categorizes exposures as high molecular weight (HMW), low molecular weight (LMW) and mixed exposures. JEM uses Standard Occupational Classification $^{7}$ published in 2010 (SOC2010) to categorize a person's job in one of 9 categories (Table 1).

\section{Statistical Analysis}

Assuming 39\% frequency of WRS based on Sadeghniiat-

Table 1. Standard Occupational Classification (SOC 2010) of Job Titles

\begin{tabular}{ll}
\hline Class $\mathbf{1}$ & Managers, directors and senior officials \\
\hline Class $\mathbf{2}$ & Professional occupations \\
\hline Class $\mathbf{3}$ & Associate professional and technical occupation \\
\hline Class $\mathbf{4}$ & Administrative and secretarial occupations \\
\hline Class $\mathbf{5}$ & Skilled trade occupations \\
\hline Class $\mathbf{6}$ & Caring, leisure and other service occupations \\
\hline Class $\mathbf{7}$ & Sales and customer service occupations \\
\hline Class $\mathbf{8}$ & Process, plant and machine operatives \\
\hline Class $\mathbf{9}$ & Elementary occupations \\
\hline
\end{tabular}

Haghighi et al study, ${ }^{5}$ 95\% CI and 6\% precision, a sample size of 250 was estimated. Demographic data, respiratory diagnosis and NIOSH respiratory questionnaire results were analyzed according to WRS. For analysis of qualitative variables, Chi-square or Fisher's exact test (for expected cell counts higher than 5) were used. For quantitative variables, normal $\mathrm{P}$ plot and Shapiro-Wilk test were applied and for normal distributions, the $\mathrm{T}$ test was used. Logistic regression analysis was done to determine the association of variables with WRS as the dependent variable. Data were analyzed by SPSS-20 and $P$ value $<0.05$ was considered as statistically significance.

\section{Results}

From January 2017 to January 2018, a total of 320 subjects enrolled, and 70 of them were excluded ( 56 subjects unable or unwilling to perform spirometry and 14 subjects not having enough data to establish a definitive pulmonary diagnosis). A total of 250 individuals (69\% male) with a mean $( \pm S D)$ age of $40( \pm 11.6)$ years were recruited for the study. Normality of the quantitative data was assessed using graphical Normal probability plot. Figure 1 shows the probability plots for age, BMI and employment duration of the participants. The proportion of job classes

Table 2. Proportion of Subjects with WRS According to Demographic, Anthropometric and Medical Data in 250 Outpatients with Chronic Respiratory Symptoms Using Chi-square test

\begin{tabular}{|c|c|c|c|c|}
\hline Variable & & Total & $\begin{array}{c}\text { WRS } \\
\text { No. }(\%)\end{array}$ & $P$ value \\
\hline \multirow{2}{*}{ Gender } & M & 174 & $66(33.7 \%)$ & \multirow{2}{*}{0.2} \\
\hline & $\mathrm{F}$ & 76 & $23(30.6 \%)$ & \\
\hline \multirow{3}{*}{$\mathrm{BMI}\left(\mathrm{kg} / \mathrm{m}^{2}\right)$} & $<25$ & 113 & $45(39.5 \%)$ & \multirow{3}{*}{0.3} \\
\hline & $25-30$ & 92 & $25(27.2 \%)$ & \\
\hline & $\geq 30$ & 42 & $25(30.4 \%)$ & \\
\hline \multirow{2}{*}{ College education } & Yes & 150 & $40(26.7 \%)$ & \multirow{2}{*}{0.1} \\
\hline & No & 120 & $49(40.8 \%)$ & \\
\hline \multirow{2}{*}{ Marital status } & Married & 203 & $74(36.5 \%)$ & \multirow{2}{*}{0.2} \\
\hline & Other & 47 & $14(29.7 \%)$ & \\
\hline \multirow{2}{*}{ Regular exercise } & Yes & 70 & $16(22.9 \%)$ & \multirow{2}{*}{$0.03^{*}$} \\
\hline & No & 180 & $71(39.4 \%)$ & \\
\hline \multirow{2}{*}{ Smoking } & Yes & 68 & $26(38.2 \%)$ & \multirow{2}{*}{0.3} \\
\hline & No & 182 & $62(34 \%)$ & \\
\hline \multirow{2}{*}{ Eczema } & Yes & 22 & $10(45.5 \%)$ & \multirow{2}{*}{$0.02 *$} \\
\hline & No & 228 & $75(34.2 \%)$ & \\
\hline \multirow{2}{*}{$\begin{array}{l}\text { Respiratory } \\
\text { medications }\end{array}$} & Yes & 219 & $72(32.9 \%)$ & \multirow{2}{*}{0.2} \\
\hline & No & 31 & $14(45.1 \%)$ & \\
\hline \multirow{3}{*}{ Job duration (y) } & $1-5$ & 69 & $23(34.5 \%)$ & \multirow{3}{*}{0.9} \\
\hline & $6-10$ & 59 & $22(37.2 \%)$ & \\
\hline & $\geq 10$ & 122 & $44(36 \%)$ & \\
\hline \multirow{2}{*}{ Personal protection } & Yes & 80 & $37(46.2 \%)$ & \multirow{2}{*}{$0.02 *$} \\
\hline & No & 170 & $53(31.1 \%)$ & \\
\hline
\end{tabular}

WRS, work-related symptoms; BMI: body mass index. $* P$ value $<0.05$. 


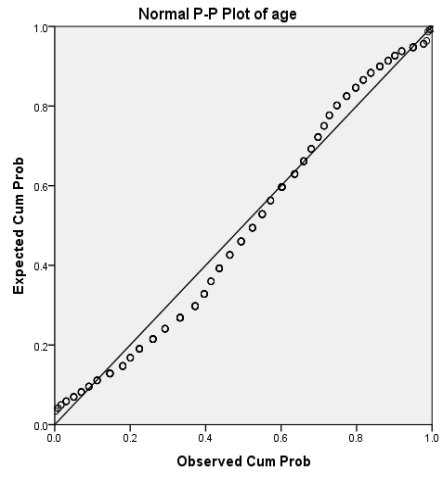

(a)

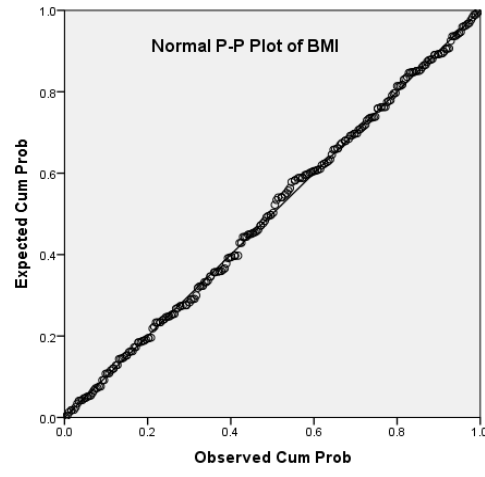

(b)

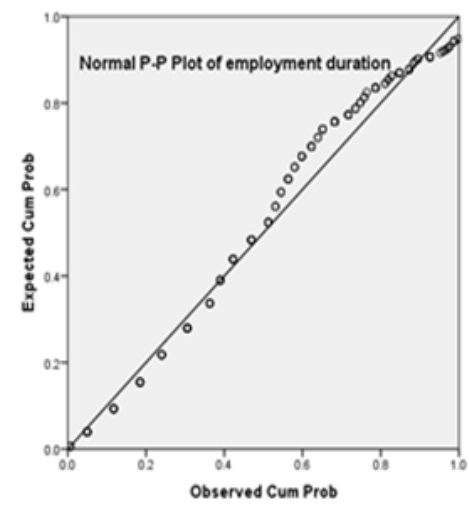

(c)

Figure 1. Normal P Plots for Age (a), BMI (b) and Employment Duration (c) of the Participants.

and respiratory diseases of the participants are shown in the figures 2 and 3, respectively. Demographic and anthropometric data of the subjects along with proportion of WRS are shown in Table 2.

JEM analysis showed a total of 128 (51.2\%) occupational exposures in our participants $(26,51$ and 51 cases with HMW, LMW and mixed, respectively). The proportion of WRS for each type of exposure was as follows: 12 (46.1\%) in HMW, 28 (54.9\%) in LMW and 15 (29.4\%) in mixed, with statistical significance only in LMW $(P=0.002)$. Those who exercised regularly showed less work-related respiratory symptoms than those who did not exercise (24.6\% vs. $39.4 \%)$. WRS was also higher in those with a history of eczema in comparison to those without eczema (62.5\% vs. 33.6\%). WRS was higher in those who currently used personal protective measures (46.2\% vs. $31.1 \%)$. Gender, smoking, BMI and use of respiratory medications were not different between those with and without WRS.

Correlations of occupational exposure for different diagnoses and disease severity are shown in Table 3. Although the most frequent diagnosis in our participants was bronchial asthma with 178 cases $(71.2 \%)$, occupational exposures were more common in COPD $(74.6 \%$ vs. 45.5\%). LMW and mixed exposure were more common in asthma and COPD (22.4\% and $37.2 \%$, respectively).

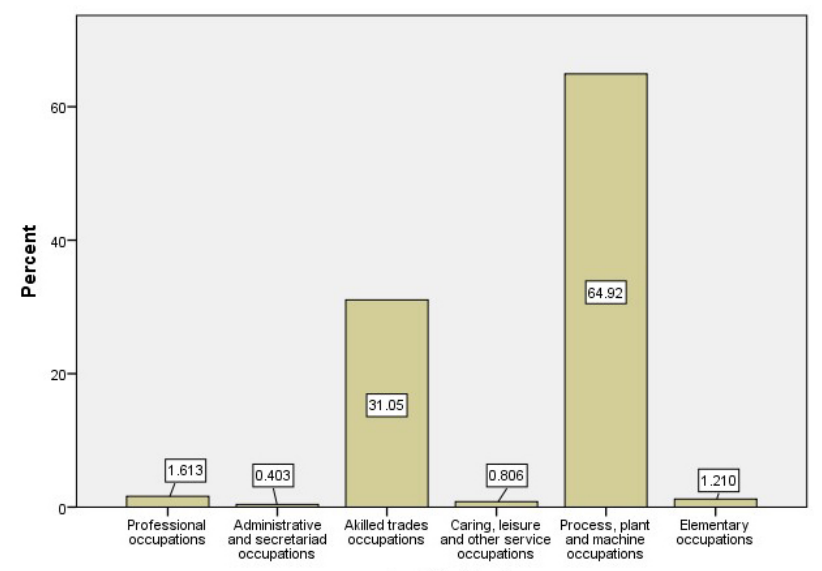

Figure 2. Frequency of Occupation Categories of the Participants.
Mixed exposure was significantly higher in COPD than asthma $(37.2 \%$ vs. $15.1 \%, P=0.001)$. According to $\mathrm{FEV}_{1}$, most of our patients were in the mild group. There was no correlation between disease severity and type of exposure. A statistically significantly higher proportion of patients exposed to LMW had WRS ( $54.9 \%$ vs. $31.3 \%, P=0.002$ ).

Table 4 shows the distribution of job class and proportion of HMW, LMW and mixed weight exposures according to JEM. Most of our participants (95.9\%) were from classes 5 (skilled trade occupations) and 8 (process, plant and machine operatives). Mixed exposure was significantly more common in process, plant and machine operatives workers $(P=0.001)$; however, as our cohort was not equally distributed across different classes, this finding has not worth much.

We also used regression analysis to determine the odds ratio of variables with respect to prediction of work-related respiratory symptoms. Age, eczema, regular exercise, education level, LMW exposure and personal protection were included in the regression and "multivariable logistic regression" was applied to assess the probable association of variables with WRS.

Table 5 demonstrates that having eczema has an odds ratio of 4.13 (95\% CI 1.3 to $12.9, P=0.01$ ) for WRS. Exposure to LMW particles tripled the risk of WRS (OR

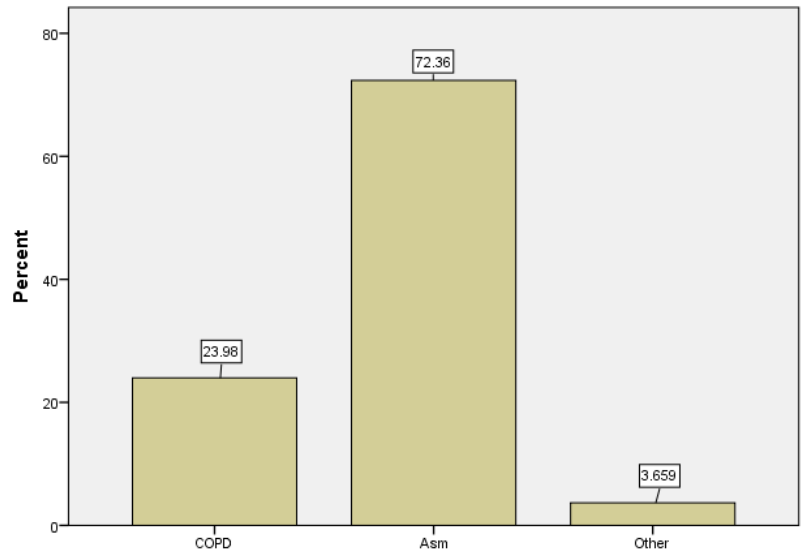

Figure 3. Frequency of Respiratory Diseases Evaluated in the Study. 
Table 3. Type of Occupational Exposure According to Job Exposure Matrix Classification for Different Diagnoses and Disease Severity

\begin{tabular}{cccccc}
\hline \multirow{2}{*}{ Different Diagnoses and Disease Severity } & Total & $\begin{array}{c}\text { HMW } \\
\mathbf{n}(\mathbf{\%})\end{array}$ & $\begin{array}{c}\text { LMW } \\
\mathbf{n}(\mathbf{\%})\end{array}$ & $\begin{array}{c}\text { Mixed } \\
\mathbf{n}(\mathbf{\%})\end{array}$ \\
\hline \multirow{3}{*}{ Diagnosis } & Asthma & 178 & $14(7.8 \%)$ & $40(22.4 \%)$ & $27(15.1 \%)$ \\
\cline { 2 - 5 } & COPD & 59 & $11(18.6 \%)$ & $10(16.9 \%)$ & $22(37.2 \%)$ \\
\cline { 2 - 6 } & Other & 13 & $1(7.7 \%)$ & $1(7.7 \%)$ & $1(7.7 \%)$ \\
\cline { 2 - 5 } & Mild & 179 & $16(8.9 \%)$ & $33(18.4 \%)$ & $33(18.4 \%)$ \\
\cline { 2 - 5 } $\begin{array}{c}\text { Severity of chronic } \\
\text { respiratory disease }\end{array}$ & Moderate & 22 & $4(18.1 \%)$ & $8(36.3 \%)$ & $6(27.2 \%)$ \\
\cline { 2 - 5 } & Moderate to severe & 15 & $1(6.6 \%)$ & $3(20 \%)$ & $4(26.6 \%)$ \\
\cline { 2 - 5 } & Severe & 0 & $0(0 \%)$ & $0(0 \%)$ & $0(0 \%)$ \\
\hline
\end{tabular}

HMW, high molecular weight; LMW, low molecular weight; COPD, chronic obstructive pulmonary disease.

"Differences in WRS prevalence between respiratory diagnoses and or their severity were not statistically significant.

${ }^{* *}$ Other chronic respiratory diseases included 11 cases of bronchiectasis, 1 case of interstitial pulmonary fibrosis and 1 case of sarcoidosis.

2.9, $95 \%$ CI 1.4 to $5.9, P=0.003$ ) in our patients.

\section{Discussion}

Our study evaluated the type of work-related exposures by JEM in cases referred to a pulmonary clinic with chronic lower respiratory symptoms.

Job categories (SOC2010 classification) showed that

Table 4. Proportion of HMW, LMW and Mixed Weight Exposures According to Job Exposure Matrix in 250 Subjects with Chronic Respiratory Symptoms

\begin{tabular}{ccccc}
\hline SOC Job Class* & Number & $\begin{array}{c}\text { HMW } \\
\boldsymbol{n}(\%)\end{array}$ & $\begin{array}{c}\text { LMW } \\
\boldsymbol{n}(\%)\end{array}$ & $\begin{array}{c}\text { Mixed }^{* *} \\
\boldsymbol{n}(\%)\end{array}$ \\
\hline Class 1 & 0 & 0 & 0 & 0 \\
\hline Class 2 & 4 & 0 & 0 & 0 \\
\hline Class 3 & 0 & 0 & 0 & 0 \\
\hline Class 4 & 2 & 0 & 0 & 0 \\
\hline Class 5 & 77 & 12 & 23 & $1(1.2 \%)$ \\
\hline Class 6 & 2 & 0 & $1(50 \%)$ & 0 \\
\hline Class 7 & 0 & 0 & 0 & 0 \\
\hline Class 8 & 161 & $13(8 \%)$ & 25 & $50(31 \%)$ \\
\hline Class 9 & 4 & $1(25 \%)$ & $1(25 \%)$ & 0 \\
\hline
\end{tabular}

SOC, Standard Occupational Classification; HMW, high molecular weight; LMW, low molecular weight.

*Standard occupational classification classes as mentioned in Table 1.

** Difference was statistically significant in the mixed group (P value $=0.001$.

Table 5. Association of Work-Related Respiratory Symptoms to Some of the Variables According to Logistic Regression Analysis

\begin{tabular}{ccc}
\hline Variables & Odds Ratio $(\mathbf{9 5} \% \mathbf{C I})$ & $\boldsymbol{P}$ value \\
\hline Eczema & $4.13(1.3-12.9)$ & $0.01^{*}$ \\
\hline 30-45 years age & $1.29(0.6-2.6)$ & 0.4 \\
\hline Regular exercise & $1.61(0.7-3.4)$ & 0.2 \\
\hline Education: diploma & $1.33(0.6-2.6)$ & 0.4 \\
\hline Personal protection & $1.85(0.9-3.4)$ & 0.5 \\
\hline LMW exposure & $2.9(1.4-5.9)$ & $0.003^{*}$ \\
\hline
\end{tabular}

LMW, low molecular weight most our participants were skilled trade occupations and process, plant and machine operatives with a very small percentage in other job classes. This pattern of job category may not exactly represent the job pattern of a healthy general population but was similar to a cohort of Iranian asthmatic population studied by Sadeghniiat et al. ${ }^{8}$

The most common chronic respiratory disorders in our patients were asthma and COPD. Multiple studies have shown the significance of occupational exposures in asthma and COPD. ${ }^{9-11}$ JEM showed that nearly half of our participants were exposed to occupational hazards with different prevalence of HMW, LMW and mixed exposure.

HMW such as latex, aerosol and plants, LMW such as wood, metals, detergents, isocyanate and mixed exposure such as metal working, fluids, textiles, and agriculture have been shown to induce both asthma and COPD. ${ }^{12}$ Both LMW and HMW have been common in asthmatic patients in other studies. Exposure to LMW, although not as common as mixed exposure, had an odds ratio of 2.9 for work-related respiratory symptoms. LMW exposure was more common in our asthmatic patients and all patients (asthma and COPD) had more work-related symptoms in the LMW type of exposure ( $54.9 \%$ vs. $31.3 \%, P=0.002$ ). COPD cases showed more occupational exposures, mainly of the mixed type. Type of exposure was not significantly different between asthma and COPD in our study. Meca et al showed that LMW caused more severe asthma than HMW exposure. ${ }^{13}$

Those patients who exercised regularly had less workrelated respiratory symptoms in our study which can be explained in the opposite direction; in other words, those with more work-related symptoms were less likely to be able to exercise regularly. Although disease severity (according to $\mathrm{FEV}_{1}$ ) was not related to the prevalence of WRS, the six-minute walk distance test could be used as the preferred method of assessment of exercise and WRS relation.

The same explanation can be applied for the higher incidence of WRS in those who used personal protective measures such as face masks at workplace. We hypothesized that those with more work-related 
symptoms use protective measures more often in order to reduce their respiratory symptoms.

Our study also showed that those with a history of eczema showed more WRS. The prevalence of eczema has been high in other studies. The lifetime prevalence of eczema ranged between $5.7 \%$ and $16.7 \%$ among women and between $5.2 \%$ and $9.5 \%$ among men in a study by Montnémery et al. ${ }^{14}$ Eczema and atopic asthma have common allergic pathways that can make the patient more susceptible to work-related respiratory symptoms. Eczema also increased the risk of having work-related respiratory symptoms by nearly 4 folds in our patients.

Assessment of airway and systemic inflammation by the methacholine challenge test for assessment of airway hyper-responsiveness or expired nitric oxide could help us to postulate hypothetical pathway for this finding. ${ }^{15}$

The study had some limitations. The participants were among outpatients of a teaching pulmonary clinic so the results should not be generalized to all respiratory patients. Also, the incidence-prevalence bias could be considered due to natural exclusion of patients with severe disease. The most important strength of the study was applying a detailed JEM and the thorough evaluation of the occupational history of the patients.

This study showed a high prevalence of work-related exposure in pulmonary clinic patients. More than half of our patients were in contact with HMW, LMW or mixed occupational exposures which are usually underestimated by physicians. We also found that JEM in conjunction with the NIOSH respiratory questionnaire are useful tools in differentiating those with and without occupational exposures and specifying the type of exposure. Management of exposure in chronic respiratory disease will help with better management of patients.

Pulmonologists are firmly advised to take their patients' occupational and vocational exposures into consideration for treatment plans.

\section{Authors' Contribution}

This study (the main conceptual idea and proof outline( was devised by LAS. Data collection was carried out by AM under guidance of MA, FR and RB. Statistical Analysis was performed by HE. RH wrote the manuscript with advice from MA and LAS.

\section{Conflict of Interest Disclosures}

There is no conflict of interest to be declared by the authors.

\section{Ethical Statement}

The study protocol was approved by the ethics committee of MUMS and was in concordance with the declaration of Helsinki (ethics code ir.mums.fm.rec.1395.496).

\section{Acknowledgement}

This study was done with grant support of vice chancellor of research, Mashhad University of Medical Sciences.

\section{References}

1. Golbal asthma report website. 2017. Available from: http:// globalasthmareport.org/. Accessed September 2018.

2. International COPD burden website. 2017. Available from: www.who.int/respiratory/copd/burden/en/. Accessed April 2018.

3. European lung organization website. Access Date: 09/11/2021. 2017. Available from: www.europeanlung. org/en/lung-disease-and-information/lung-diseases/ occupational-lung-disease. Accessed April 2018.

4. Miller MR, Hankinson J, Brusasco V, Burgos F, Casaburi $\mathrm{R}$, Coates A, et al. Standardisation of lung function testing: the authors' replies to readers' comments. Eur Respir J. 2010;36(6):1496-8. doi: 10.1183/09031936.00130010.

5. Sadeghniiat-Haghighi K, Aminian O, Najafi A, Salehpour S, Eslaminejad A, Derakhshan Deilami G, et al. Work-related exacerbation of asthma among adults treated by pulmonary specialists. Arch Environ Occup Health. 2016;71(1):35-42. doi: 10.1080/19338244.2014.941094.

6. Kennedy SM, Le Moual N, Choudat D, Kauffmann F. Development of an asthma specific job exposure matrix and its application in the epidemiological study of genetics and environment in asthma (EGEA). Occup Environ Med. 2000;57(9):635-41. doi: 10.1136/oem.57.9.635.

7. Maughan ED, Effken J, Cochran K. Standard occupational classification codes: an update. Comput Inform Nurs. 2017;35(5):226-7. doi: 10.1097/cin.0000000000000360.

8. Sadeghniiat K, Aminian O, Najafi A, Salehpour S, Eslaminejad A, Derakhshan Deilami G, et al. Prevalence of work-related asthma among adult asthmatics referred to pulmonary clinics. Eur Respir J. 2012;40(Suppl 56):P1031.

9. Chen JC, Mannino DM. Worldwide epidemiology of chronic obstructive pulmonary disease. Curr Opin Pulm Med. 1999;5(2):93-9. doi: 10.1097/00063198-19990300000003.

10. Vinnikov D, Rybina T, Strizhakov L, Babanov S, Mukatova I. Occupational burden of chronic obstructive pulmonary disease in the Commonwealth of Independent States: systematic review and meta-analysis. Front Med (Lausanne). 2020;7:614827. doi: 10.3389/fmed.2020.614827.

11. Le Moual N, Carsin AE, Siroux V, Radon K, Norback D, Torén K, et al. Occupational exposures and uncontrolled adult-onset asthma in the European Community Respiratory Health Survey II. Eur Respir J. 2014;43(2):37486. doi: 10.1183/09031936.00034913.

12. Beach J, Burstyn I, Cherry N. Estimating the extent and distribution of new-onset adult asthma in British Columbia using frequentist and Bayesian approaches. Ann Occup Hyg. 2012;56(6):719-27. doi: 10.1093/annhyg/mes004.

13. Meca O, Cruz MJ, Sánchez-Ortiz M, González-Barcala FJ, Ojanguren I, Munoz X. Do low molecular weight agents cause more severe asthma than high molecular weight agents? PLoS One. 2016;11(6):e0156141. doi: 10.1371/ journal.pone.0156141.

14. Montnémery P, Nihlén U, Löfdahl CG, Nyberg P, Svensson A. Prevalence of hand eczema in an adult Swedish population and the relationship to risk occupation and smoking. Acta Derm Venereol. 2005;85(5):429-32. doi: 10.1080/00015550510036658.

15. Lipińska-Ojrzanowska A, Marcinkiewicz A, WalusiakSkorupa J. Usefulness of biomarkers in work-related airway disease. Curr Treat Options Allergy. 2017;4(2):181-90. doi: 10.1007/s40521-017-0121-9. 